Article

\title{
Barriers to Higher Education for Students with Bipolar Disorder: A Critical Social Model Perspective
}

\author{
Allison K. Kruse and Sushil K. Oswal * \\ School of Interdisciplinary Arts and Sciences, University of Washington, Tacoma, WA 98402, USA; \\ E-Mails: allisonkkruse@gmail.com (A.K.K.), oswal@u.washington.edu (S.K.O.) \\ * Corresponding author
}

Submitted: 6 July 2018 | Accepted: 29 August 2018 | Published: 6 December 2018

\begin{abstract}
Employing some of the features of participatory research methodology, a disabled faculty joins a student with mental health diagnosis to examine the factors that hinder or enable success for this group. The theoretical framework or scholarly bearings for the study comes from the critical social model of disability, disability services scholarship in the United States, and education theory literature on "student success". With a particular focus on students with bipolar disorder, the article highlights the gaps in disability scholarship on this specific group while underscoring the oppression experienced by them through the inclusion of an autoethnographic segment by the primary author in this collaborative, scholarly work. The model of access, we propose, moves beyond accommodations-which are often retrofits or after the thought arrangements made by an institution-and asks for environmental support, social and institutional inclusion, and consideration for students with psychiatric health diagnosis. This article not only presents an array of problems in the United States academy but also a set of recommendations for solving these problems. Going beyond the regime of retrofit accommodations, we ask for an overhaul of institutional policies, infrastructures, and curricula so that the academy is inclusive of neurodiverse bodies and appreciates their difference.
\end{abstract}

\section{Keywords}

academic ableism; autoethnography; bipolar disorder; critical social model; disability; disability accommodations; disclosure in higher education; psychiatric health diagnosis; retrofits; student success; students with mental disabilities

Issue

This article is part of the issue "Students with Disabilities in Higher Education", edited by Geert Van Hove (Ghent University, Belgium/VU Amsterdam, The Netherlands), Minne Bakker (VU Amsterdam, The Netherlands) and Alice Schippers (Disability Studies in the Netherlands/VU Amsterdam, The Netherlands).

(C) 2018 by the authors; licensee Cogitatio (Lisbon, Portugal). This article is licensed under a Creative Commons Attribution 4.0 International License (CC BY).

\section{Introduction: An Overview}

This article examines the needs of students with mental health diagnosis in post-secondary education through the scope of bipolar disorder and suggests changes that may promote an accessible pedagogy and assist in the inclusion of students with mental disabilities in the academy. The focus on bipolar disorder is important because very little research has been published on this student group's specific needs (Demery, Thirlaway, \& Mercer, 2012; Donaldson, 2015). In doing so, this ar- ticle advances several of the goals of this special issue by addressing mental disability, such as: 1) a student and an instructor taking the slogan, "nothing about us without us", to heart by co-authoring a participatory research article to explicate the experiences of students with mental disabilities; 2 ) critique how faculty and staff in higher education view performance of students with and without disabilities from their privileged spaces and cultivate an unfriendly academic climate of ableism; and 3) expand the methodological toolkit within qualitative research by employing in an intersectional manner meth- 
ods from Disability Studies including, a disability narrative, personal reflections, and the use of medical and critical social models of disability to frame this discussion that collectively make connections between lived experiences of disabled students and how they are restricted by social and physical structures, institutional policies, and ableist norms.

\subsection{Critical Social Model of Disability}

We employ the critical social model of disability as a lens for our discussion throughout this article, which is based on an earlier model of disability sometimes known as the social model of disability (Union of the Physically Impaired Against Segregation, 1976). Social model of disability, which bifurcated disability into two by separating biological condition or impairment from disability, was put forth to sever disability from the clutches of medical establishment and to draw political attention to the socio-economic barriers experienced by the individual. However, the social model ignored the demands of many physical and mental impairments on the body. It also overlooked the dependencies an impaired body might have on professionals for medicine, day-to-day care, and other survival functions (Crow, 1996; Morris, 1991). We find the reasoning of the critical social model, therefore, meaningful for several reasons in the context of mental disability in the academy. First of all, critical model questions the sharp division of "impairment" and "disability" by the social model and its recognition of dependencies. Impairment-temporary or permanentresulting from a mental disorder is real and it cannot be separated from the social disability experienced by the individual due to the physical and societal barriers (Ghai, 2003; Priestley, 1995; Shakespeare \& Watson, 2001). For example, a student with bipolar disorder can be dysfunctional during a difficult episode of illness or might need specific accommodations for the resulting impairment to function adequately in or outside the class. Impairment is of central concern for the student to survive in the highly competitive environment of the university. Individuals with mental disabilities also can't distance themselves from the medical establishment to the extend the old social model did because they depend on medical professionals for their needs for medicine, therapy, and counseling. Under the neoliberal regimes of the recent decades, the welfare state has been diminishing in the industrialized countries and many students experience conditions of poverty, lack of adequate healthcare, and general depravation commonly associated with developing countries.

\subsection{Unwelcoming Institutional Conditions for Students with Mental Health Diagnosis}

We stress that institutional standards of accommodation and assistance for students with mental disabilities are in place, and have been in place for decades; however, students with mental disabilities still choose, in overwhelming numbers, to leave their mental disability in the closet. Further, the stigma attached to mental disabilities, lack of knowledge/training/experience among faculty and staff, and a difficult accommodations process deter students from living openly with their disability, thus setting them up for failure (for this neglect of disabled students in general in higher education see the extensive literature review by Kimball, Wells, Ostiguy, Manly, \& Lauterbach, 2016; for a detailed treatment of the concept of "stigma", see also Goffman, 1963/2009). This failure is shown by the excessive number of student dropouts with bipolar disorder even before they had a chance to apply their abilities in their studies. By exploring the experiences of a student with bipolar disorder, the ableist assumptions of our society, and gaps in the current support policies and processes, this article not only presents an array of problems but also a set of recommendations for tackling with these problems. The model of access, we propose, moves beyond accommodations-which are often retrofits or after the thought arrangements made by an institution-and asks for environmental support, social and institutional inclusion, and consideration for students with mental health diagnosis. The model of access we argue for demands an overhaul of institutional policies, infrastructures, and curricula so that the academy is inclusive of neurodiverse bodies and appreciates their difference. These changes can produce physical and learning environments in which disability accommodations are unnecessary or needed only infrequently. This model also advocates that the disabled person's agency always remains intact when they have to avail of accommodations because of the persisting ableist institutional policies and structures. We want to point out that we intentionally avoid making a legal argument to make our case because the extensive literature on judicial decisions from the United States indicates that the courts might not be the best place for seeking support for students with psychiatric disabilities (Kiuhara \& Huefner, 2008). Instead, we appeal to universities to make reasonable modifications in their rules, policies, structures, and practices to include the student needs and show concern for their well-being as full-fledged members of the academic community. We further ask educators to abandon the deficit view of students with mental disabilities and focus on the assets they bring to our classes through their neurodiversity, their persistence to succeed, and their real-world struggles as human beings (Dinishak, 2016).

We begin by defining the various assumptions about mental disability in higher education from the perspective of critical social model of disability and how these assumptions create and sustain stereotypes that prevent disabled students from achieving their academic, career, and social goals (Oswal, 2018). Working from this critique, we develop a discussion on how the very disclosure process that all disabled students must maneuver through to become eligible for accommodations and of- 
ten erratic and sometimes unreliable implementation of these accommodations by faculty in the classroom pose barriers to receiving equal learning opportunity. After showing how the ableist assumptions about mental disability by medical and disability services professionals can contribute to the systemic oppression of students with mental disabilities, we make recommendations to university educators for removing these barriers that can prevent the learners with bipolar disorder from achieving their dream of a college degree. While our descriptions of mental disabilities and the discussion of the institutional and pedagogical barriers come from our lived experiences-the primary author is a student with a mental health diagnosis and the second author is a faculty with long-term experience of receiving and giving disability accommodations on six different campuses in the United States-the vast literature on disabled students in higher education documents that many of these issues also materialize in one or other form on college campuses around the globe (Kimball et al., 2016). Likewise, the variations of these issues have been documented in the experiences of disabled faculty in the United States and elsewhere although we limit our discussion here to the concerns of students with psychiatric health diagnosis (Kerschbaum et al., 2013). We also want to note that the disability-related terminology used throughout this article alternates among "students with mental disabilities", "students with mental health diagnosis", "mental illness", "mentally disabled students", and "disabled students" to reflect the prevalence of diverse labels in the published literature and the differing preferences students show for these labels.

\section{Background Data}

According to the National Institute of Mental Health (2006), approximately $25 \%$ of all Americans experience a diagnosable psychiatric disability each year. The selfreported data by college students match these national numbers (Sharpe, Bruininks, Blacklock, Benson, \& Johnson, 2004). Out of all the students enrolled in colleges in the United States in 2011-2012, more than 11\% had a disability, and out of this population of disabled students, almost every one in four had a mental disability (National Center for Education Statistics, 2016). According to an earlier National Survey of Campus Disability Services, up to $86 \%$ of students with mental disabilities may never finish their college degree (Collins \& Mowbray, 2005).

\section{Mental Disability and Academia}

The onset of mental disability often occurs from ages 17 to 25 , and so many students with mental disabilities are experiencing symptoms for the first time as they enter college (Collins \& Mowbray, 2005; Mullins \& Preyde, 2013). In order to receive accommodation for mental disability, students are required to disclose their disability, provide appropriate documentation, and then enter a negotiation process with their professors. However, the majority do not disclose and do not seek accommodation (Clark, 2006; Collins \& Mowbray, 2005; Demery et al., 2012; Venville, Street, \& Fossey, 2014). One specific deterrent to disclosure and seeking treatment is stigma, which is created by ableist assumptions that those with mental disabilities are violent, unstable, and unsuited for academic environment (Eisenberg, Downs, Golberstein, \& Zivin, 2009; Price, 2011). The protected value of competition in academia also presents the barrier that a student may be accused of or believed to be lying about her disability in order to receive "extra help" over her peers, or even rejection on the grounds that accommodation for the disability creates an unfair advantage within the classroom. (Clark, 2006; Price, 2011).

\section{Bipolar Disorder}

Bipolar disorder (also termed bipolar affective disorder) is defined by the World Health Organization's (1992) International Classification of Diseases (ICD-10) as:

Characterized by repeated (i.e., at least two) episodes in which the patient's mood and activity levels are significantly disturbed, this disturbance consisting on some occasions of an elevation of mood and increased energy and activity (mania or hypomania), and on others of a lowering of mood and decreased energy and activity (depression). Characteristically, recovery is usually complete between episodes, and the incidence in the two sexes is more nearly equal than in other mood disorders.

While little information has been collected on students with bipolar disorder, the symptoms have been documented. While we don't include the full range of symptoms that people with bipolar disorder experience, we include symptoms with needs that are not met by the current academic system. Most information from this section has been taken from Nitzburg et al. (2016) in their study "Coping Strategies and Real-World Functioning in Bipolar Disorder".

Students with bipolar disorder are at a high risk to respond to adversities - in this case, the disclosure, accommodation, and education process - with "maladaptive coping strategies", including dropping out, self-blame, and substance abuse, another common mental disability in post-secondary education with highly unmet needs for treatment (Blanco et al., 2008). The "giving up" coping strategy was seen throughout studies in which most bipolar students did not complete their education (Blanco et al., 2008; Venville et al., 2014). Verbal ability also can be impaired significantly by symptoms of bipolar disorder. Additionally, people with bipolar disorder are extremely affected by the conditions of their environment-particularly the ableist environment that enforces blame on the disabled person and not society. 


\section{5. "But There Are Already Places for the Mentally Disabled, Right?"}

Most colleges today have some sort of student health center with resources for students who may have a mental disability. However available and accessible these centers are, a large number of students with mental disabilities will not seek help or treatment due to the perceived stigma. Rhetoric scholars of disability, however, remind us of the relevance of narrative genre for giving voice to those lacking authority "to speak against dominant perceptions of mental illness" (Pryal, 2010, p. 499). Our research design and analysis are further based on the understanding that the voices and lived experiences of those who are seen on the receiving end of services, education, and support can offer rarely recognized but equally crucial, on-the-ground knowledge (Roets, Kristiansen, Van Hove, \& Vanderplasschen, 2007; Trivedi \& Wykes, 2002). Likewise, feminist theorists have pointed out that when the "personal becomes political" the researchers can make better connections between personal narratives and historical, societal, and institutional structures of power (Thomas, 1999). Thus, personal narratives are a crucial tool for the process of selfempowerment (Barton, 1998, p. 37).

Here, one of us narrates our own experience of seeking help through our educational institution to demonstrate the unmet needs of students with mental disabilities when they may need help.

\subsection{Personal Experience}

In reaching the stage of receiving the actual help for my bipolar disorder, that is, my first session with a counselor, the student help center took nearly two months. My prolonged wait is only one example of many such experiences with every campus enrolling dozens and dozens of students with mental disabilities. Looking back, I realize that the extended period of time it may take to be seen for the first time can be just as debilitating for a student with bipolar disorder than no help at all.

I remember the receptionist being friendly, but I also remember distinctly the way that she looked at me: like I might throw myself out that fourth story window at any minute. The look alone made me want to turn around and leave. Many students with mental disabilities fear stigma the most out of all repercussions of disclosure, and I was looking stigma in the face before I even had the chance to disclose-in a way, my being there in the first place was disclosure enough, and assumptions had already been made. This, too, can act as a powerful deterrent to students with mental disabilities.

I explained to her that I wanted to be seen by one of the counselors, and she told me she would send me an email with a questionnaire. This was to determine if my mental state was more fragile and urgent than the unknown (but apparently large) number of students who had filled it out before me. I would then be called by one of the doctors within a few weeks to discuss some further questions. If a system put in place to help students tells those same students to "take a number" when they need help, the system may only strengthen the already-present feelings of self-deprecation and wanting to give up that the very system is put in place to fight. And there, as I was experiencing one of the most debilitating and intense depressions I had ever experienced, I was told to "take a number".

The day the doctor called, I was on my 30th hour in bed; I had spent 24 of them sleeping. I hadn't attended classes in nearly a week. I picked up on the very last ring, after internally talking myself out of the belief that it didn't matter, that they weren't going to help me; that I was beyond help. The doctor answered, verified my name, and then began this series of questions: have you seriously considered ending your own life in the past week? Have you made plans to end your own life in the past week? How often do you drink alcohol? Have you seriously considered harming yourself or others in the past week? This phone call itself embodied the issues of what Disability Studies scholars call the medical model of disability (Oswal, 2018). I was a piece of paper with checked boxes, determining whether or not I was mentally ill "enough" to be considered for assistance.

I tried to answer honestly, knowing that each checked or un-checked box was going to influence my chances of being helped. The anxiety had convinced me that I had failed one of my courses already due to my absences, my anxious and depressive states, and my inability to think of anything but my own hysteria in class. I just wanted help. But as I answered the questions to the monotone man on the other line, I felt less and less like a person.

My call was returned two weeks later, and they had decided I should be seen "immediately" but my appointment was set for two more weeks out. I wanted to be relieved or happy, my depression reminded me that the only reason I was getting help was because I was "sicker" than the rest of them. Additionally, I couldn't help but wonder how many students had to lose their opportunity for help just so I could get mine; how many students would never have their "number" called. The guilt followed me deeply during my depressive states and proved to be almost as debilitating as the shame that came with being considered "more mentally ill" than the rest.

The help that I received following this process was my own accommodation, and I was able to complete my academic year with the help of weekly sessions with a counselor. I share this narrative not to say that the system my school offered did not help students at all who needed help, rather that the system we have in place at my school (and many others) still has much room for improvement before it is truly for the mentally disabled.

\subsection{Analysis: Stigma and Process as Deterrents for Seeking Help}

Here, we would like to discuss two reasons that students do not approach these mental health centers for treat- 
ment: stigma surrounding mental illness, especially in college students, is extreme and unforgiving, and the process to be seen and helped is often extensive, impersonal, and lengthy, and during this process the students are evaluated to determine whether they are disabled "enough" to require care. The story here also shows the aforementioned processual barriers between mental disability and seeking care in academia: stigma, time, and seeking proof that someone is disabled "enough" (Goffman, 1963/2009).

The demeanor of the receptionist upon meeting and speaking with the student carried a few problematic assumptions about mental disability: that the student was perpetually on the edge of a violent outburst (toward her or others), that it was appropriate to express pity or sadness on her behalf, and that she was to be treated differently (with a softer voice or gentler words). This fear is an extreme deterrent particularly for students with disorders that affect their self-esteem or social capabilities. One of the biggest fears students have about seeking help for a mental disability is how stigma will affect the way they are treated, and without even being seen, diagnosed, or evaluated, the student was already being treated differently because she believed that she was mentally disabled. This is not to say that the receptionist was unkind or deliberately attempting to deter this student's quest for help: in fact, the student left the office angry not at the staff, but at the commonsense assumptions that it is appropriate (or best) to respond in that way.

Moreover, the six weeks that the student was required to wait before she even knew if she qualified for care is another extreme deterrent for many students with mental disabilities seeking care, particularly students with bipolar disorder. In the case of bipolar disorder, moreover, conditions and symptoms constantly change and can be unpredictable. A student willing to seek help one day may find an onset of symptoms the next day that prevents her from seeking help. In the primary author's case, the symptoms clearly almost prevented her from completing the application process midway due to an onset of a major episode of depression.

The series of impersonal and category-infested surveys students are required to fill out further demonstrate one of the most problematic assumptions about disabled people: that you must fit into a specific category and you must be in a fixed state of disability to receive help. The fact is that disability lives on a spectrum and people with bipolar disorder go through different experiences, feelings, emotional and mental barriers, successes in overcoming these hurdles, at different times in their day-today lives, and all or some of these might situate an individual somewhere at a different point on this spectrum that depicts from most extreme to some very mild states of impairment and disability. For example, a student with a mental disability may be suffering in all aspects of life on one day: her bipolar disorder might prevent her from attending class, participating in online group projects, or leaving her home to go to work, and this student may never experience violent thoughts in her life. Should she choose to seek help, she may have to face the assumption that her disability is not detrimental enough to require help, despite the fact that she is facing the loss of her academic career, job, etc. The point here is not limited to whether or not universities provide adequate help sooner or later, it is also about whether or not universities show an understanding of the experiences of a student with bipolar disorder and make an effort to match the delivery of their services to that experience. In practical terms, it could mean that the student would not only receive counseling when it is needed but also that the professor would say that the student doesn't have to submit that major assignment exactly on Friday midnight and its completion could wait until she can recover. When disability services offices and faculty insist on a set standard formula for additional time to complete an assignment as an accommodation, they fail to notice the nuances of bipolar disorder as a disability. They don't realize that a student with bipolar is not asking for additional time because it takes them longer to write in braille or typing on a keyboard because of their hand-motor disability; instead their time clock is tied to the onset and departure of an episode and while they are in the grip of it.

\section{Implications of an Ableist Environment}

Ableism is defined as the societal attitudes that devalue and disregard people with disabilities (Oswal, 2013). Others have described ableism as "denoting an attitude that devalues or differentiates disability through the valuation of able-bodiedness equated to normalcy" (Campbell, 2009, p. 5). Ableism has influenced the way we view accessibility by the belief that society should center around what a "normal" person is: entirely healthy and able-bodied. Because of this belief, equal access for those who are not considered "normal" is seen as excessive or unfair (Boys, 2014). Ableist society believes that those with disabilities can be (and should be) able to "overcome" the barriers of their disabilities and succeed by "normal" standards, regardless of the fact that the barriers they face are often created by society and not their disability (Chrisman, 2011; Oswal, 2018; Runswick-Cole \& Goodley, 2013). Even in this second decade of the 21st century, university faculty can choose to play self-styled disability therapists in the face of all disability rights and can coerce disabled students to adapt to their ableist pedagogies For an example, see the heavy-handed treatment of a student with an invisible disability by a senior professor about giving accommodations in her class in an article by Hornstein (2017) in The Chronicle of Higher Education. For instance, when faculty members insist that all students must employ the same modality at the same pace, they are asking students with disabilities - who might possess a different body or mind-to perform on a rigid ableist scale and 
they forget that the same learning goals can be achieved using different means at a different pace. In the same vein, when university faculty enforce the mandatory attendance policy on all students as a universal requirement, they forget that a bipolar body and/or mind simply might not be in a shape to obey their edict on a particular day of class (for a comprehensive treatment of compulsory attendance policy and its implications for the disabled in the academy, see Nicolas, 2017).

More than anything, faculty need to be shown that well-meaning interactions often pose serious problems to students with disabilities and they need to work with disabled students and not work at them. Because of expectations to overcome and not resist, many disabled people choose to pass as "able" and endure the difficulties of their disability in private on top of the exhausting demand of constantly working to hide a disability (Boys, 2014; Price, Salzer, O’Shea, \& Kerschbaum, 2017). In spite of the national disability laws in most industrialized countries for over a quarter century, colleges and universities continue to formulate policies that ignore the needs of disabled students, faculty, and staff, build inaccessible infrastructure, teach exclusionary curriculum using ableist pedagogies, and publish scholarship that either ignores disability, or exhibits ignorance about it (Grasgreen, 2014; Jones \& Brown, 2012; Oswal, 2017).

\subsection{Mental Disability in an Ableist Academia}

In order to understand specific issues in regard to mental disability in academic life, it is important to understand that the overall issues regarding mental disability are no different in our larger society than in academia except that the university itself is an elite and exclusive institution. Critical social model of disability, that places equal emphasis on socially-constructed disability and individual's impairment, offers us a useful lens to study the physical needs of the students and the social context of receiving help (Oswal, 2018). Stigma, or shame associated with mental disability, is a common problem among mentally disabled students, as the common social stereotypes associated with mental disability work to marginalize the mentally disabled in society.

Some of the stereotypes regarding mental disability are: 1) the belief that one can only be abled or disabled, with no gray area or in-between; 2) disabled people are exempt from rules of appropriate social interaction or require pity, concern, help, etc., at all times; 3) disability can be categorized and cured accordingly, and these cures work universally for disabilities within a certain category; and 4) disability is an individual problem.

Mental disability is often overlooked or doubted in academia because of the unpredictability of symptoms. Disability has been framed as a box that is checked or un-checked and must be manifested at all times and in all circumstances in order to qualify as "disability" in the first place, despite the fact that mental disability is not so simple or clean-cut a state in lived experience.
Assumptions about the lives and feelings of disabled people have also created the added assumption that abled-disabled social interaction is governed by different rules than those of "normal" people (Silvers, 1994). "Invisible" disabilities, such as mental disabilities, are often kept invisible through passing due to the new and invasive rules of social interaction that further work to marginalize the student with a mental disability. In addition, the disabled person's right to privacy is assumed to dissolve with her disability, as a college staff member may offer invasive suggestions: "my sister was diagnosed with bipolar disorder, you should try this medication". By disregarding the respect that would be expected in a conversation with a non-disabled person. Such behaviors further marginalize mentally disabled people by inadvertently showing “they aren't normal, so they don't need to be treated that way".

Another problematic assumption in our ableist society is the belief that mental disability has been accurately broken down into scientific categories, and every disability has a medical fix. For many mental disabilities, pharmaceuticals dominate this belief system, despite a slew of more-disabling, known side effects. This becomes even more problematic when a person experiences more than one disability and is expected to take a large variety of medications.

Despite the ableist assumption that the disabled are helpless without the non-disabled, the ableist society further isolates disability by enforcing the belief that it is the disabled individual's responsibility to cope with their disability, seek help, pay for the cost of help, and live with their disability day by day, regardless of the reality that living with disability is problematic primarily due to the incorrect belief the all or most people are non-disabled or "normal". In other words, disability is only problematic because of its placement in a society designed by nondisabled people for other nondisabled people, but this ableism also governs the belief that disabled people must find a way to fit in instead of non-disabled people redefining problematic societal frameworks and infrastructures that shun or exclude disability.

At the root of these issues is also the ableist assumption that disability is over there, not here and that mental disability is a special circumstance requiring special care, not a part and parcel of everyday human life, and therefore, societal life. By creating a defining line between the so called "abled" and the "disabled", disability has been excluded from the qualifications of what constitutes "anyone". This "anyone" we are referring to here is the concept of our society that we will design, create, legislate, and live in ordinance with what "anyone" could and should do. While this marginalization may not be deliberate, it is deeply engrained into our commonsense belief systems, and is constantly working toward preventing the equality, success, and inclusion of disability in the academy. 


\subsection{Mental Disability inside the Classroom}

In this section, we specifically address how the stereotypes about mental disability have transferred into legal accommodations for disabled students in postsecondary education, and then there are additional assumptions in academia that further marginalize disability. These include: 1) accommodations process as a problem and not a solution; 2) competition as a core value of academia; 3) lack of staff training; and 4) the belief that teachers must be objective and impersonal.

Most college courses include a syllabus, and in this syllabus is a (required) disability statement, which often states that a student requiring disability accommodations must speak to the professor, provide proper paperwork from the campus disability services, and negotiate the terms of accommodation. These boilerplated disability statements prove to be one of the many not-sohelpful "quick fixes" for several reasons.

First, disclosing one's mental disability is a gamble in itself: once disclosed, this information is accessible to anyone in the academic world, and can become a problem during the student's application for a graduate program or search for a career, among others. Students who have disclosed a mental disability in order to receive accommodation have experienced a variety of consequences including the belief of the faculty writing recommendation letters that the student will not be able to handle higher-level academic programs and jobs just upon knowing the student has a disability.

Second, proper medical documentation is expected which is extremely reliant on the belief that disability must be categorized. This requirement also proves to further marginalize underprivileged students with disabilities. If a student cannot afford to undergo extensive psychiatric examination to "prove" their disability, disability accommodations will not be available from the university. Readers might note that the process cannot be completed in a single visit to the doctor, as psychiatric evaluation is often based on a series of sessions with a psychiatrist.

Third, the negotiation process can prove to be grueling and oppressive for the mentally disabled student. Even with proper documentation, this process places the power of deciding whether a person is disabled "enough" in the hands of the creator of the curriculum, who is not likely to be trained with an understanding of mental disability and has only commonsense assumptions to help judge which accommodation is appropriate. Students with "invisible" disabilities like bipolar disorder may receive little to no help during this process, as the common belief that one is either obviously disabled or not disabled influences the educator's decision.

Academia's holding of competitiveness as a ee value in its community also works against mental disability in post-secondary education. Accommodations can often be refused on the grounds that giving a student more time or eliminating the requirement of attendance will give the student an "unfair advantage" over her peers, regardless of the fact that her bipolar disorder has already given her peers an unfair advantage over her. No doubt, the course curriculum and pedagogy for the class also has been designed for the nondisabled peers in the first place and not the students with disabilities.

The issue of competitiveness as a core value can also be seen in teacher's skepticism to believe a student has an "invisible" disability at all. Skeptical responses by professors show that academia holds competition at such a high value in its community, teachers are led to believe that a student would sooner lie about being mentally disabled to gain an unfair advantage over her peers before she would likely be honest about having the disability. This belief, too, returns to the commonsense assumption that if a disability is not constant and obvious, it is non-existent.

Most of the conduct by professors to further marginalize mental disability in academia is due to lack of training and information about disability and disability studies

While K-12 educators are required some degree of training in child psychiatry-which still uses the problematic medical model of disability-college professors are not required any training in working with mentally disabled students. Despite the report that one of the biggest issues educators face in working with disabled students is not knowing how to work with them, they are still expected to teach disabled students all the same (Collins \& Mowbray, 2005). This results in the extreme disconnect in their understandings of mentally disabled life, or what may result in their belief that a student's inability to complete an assignment due to a manic episode is unbelievable.

Further on, academia fails to challenge its own ableist assumptions by enforcing the belief that teachers should be educators and educators alone which can have its own repercussions for a disabled student. In fact, the educational community discourages interpersonal relationships between teachers and students on the grounds that the "emotional burden" is not within the scope of the responsibilities of the teacher (Price, 2011). Despite this belief, a trend among successful students has been reported due to interpersonal and "friendly" relationships with their professors (Halawah, 2006).

A variety of factors attribute to the extreme stress that is placed on college students just by attending college (Davidovitch \& Soen, 2006). With the added stress of adjusting in a highly competitive academic environment-completing homework with rigid deadlines, participating in graded class discussions, and attending class itself-mental disability can be seemingly an impossible state to cope with amidst an episode. For students with bipolar disorder, the distance created between students and teachers is effectively eliminating another possible support system that could make the difference of staying in or dropping out. 


\subsection{Additional Barriers for Students with Bipolar Disorder}

As bipolar disorder is an "invisible" disability, it may also be met with disbelief and skepticism when the student chooses to disclose. The belief that one must be either abled or disabled prevents educators and faculty from understanding that, although the symptoms of bipolar disorder may be inconsistent and unpredictable, that student is still disabled and may require accommodation. It is assumed that because a student was not experiencing the symptoms of her bipolar disorder two weeks ago, she is not truly disabled.

The medical regime also threatens students with bipolar disorder with the pressure or requirement of medication, despite the fact that pharmaceuticals are only one option of many treatments. Students with bipolar disorder who do not seek pharmaceutical treatment may be subject to stigmatic repercussions by their educators, staff, and peers. Marginalization of disabled people is further cemented through the belief that those do not experience positive effects from the miraculous cures of these pharmaceuticals or methods should be cast out as the "incurable" or are then responsible for their own disability due to the refusal of pharmaceuticals or other methods, pushing them even farther from what GarlandThompson (1997) calls the world of "normates". Normates possess "the corporeal incarnation of culture's collective, unmarked, normative characteristics" (GarlandThompson, 1997, p. 8). In short, it is a standardized body imagined by a culture as perfect but never approximated by any mortal, let alone the people with disabilities.

\section{Recommendations for Reconceiving the Student-Teacher Relationship}

Students with mental disabilities are subject to the limiting structure of an academic system made by the abled, for the abled which to them appears no better than a black box whose inner mechanisms are invisible. While there are retrofit systems-systems that try to fix the problems of access after the fact, or as an add onin place to assist students with mental health diagnosis, the disability services delivery processes themselves have flaws that are more likely to deter students from seeking accommodations. We make several recommendations for improving these processes and changing the campus climate for disabled students.

\subsection{Rethinking the Academic Accommodations Process}

When students are seeking accommodations for mental disabilities and a psychiatric evaluation is not immediately possible, the university should have an alternate plan in place. Here, we emphasize that we must begin this process with the belief that a disclosure of mental disability is not a ruse to earn more leniency in class. If a student is seeking an academic accommodation and needs psychiatric evaluation to support that accommodation, the student should be given the appropriate academic accommodations during the evaluation process. Additionally, psychiatrists should be provided for students expected to undergo evaluation that do not have appropriate medical care. While most college campuses have a student counseling center in place for students seeking psychiatric care, this office needs to work closely with the disability services office to provide psychiatric evaluation to those who cannot afford it otherwise.

Second, faculty involved in handling the accommodation process must be prepared to help students whose disabilities prevent from communicating in ways that we may believe "anyone" can communicate, such as surveys or the expectation that a student will know exactly what accommodations are best for them.

Third, it is important to ensure that the process in which a student seeks accommodations is not off-putting and does not contribute to the creation of stigma and marginalization of the mentally disabled. As seen in the experience of one of us seeking accommodation in the form of regular counseling and vouchsafed by published research, the process can often be impersonal, indifferent, and difficult in an already elitist college climate (Wilson, Getzel, \& Brown, 2000). It is important to understand that many students with bipolar disorder may opt to taking lower grades, taking time off, or dropping out entirely in lieu of participating in this process, so the process itself must not be a deterrent.

Last, we also want to draw attention to the diversity among students with mental disabilities on our university campuses and their specific needs. We don't believe that the traditional multicultural competency training offered to clinical counseling staff is sufficient to meet the needs of today's university student populations (Hansen, Pepitone-Arreola-Rockwell, \& Greene, 2000). To provide adequate support to these highly diverse student groups, including a significant percentage of international students, university counseling services will do better off staffing their services with experts possessing intersectional understanding of the needs of students with mental illness diagnosis who might have other disabilities, or belong to diverse racial, ethnic, and cultural groups (Harsh, 1993; Olkin, 1999). Scholars writing about the discipline of Psychiatry have also been asking for interdisciplinary and intersectional approaches to practice so that the knowledge and meaning-making processes of other disciplines could be availed by the field of counseling to make it less clinical and more human (Carel, 2012, 2017).

\subsection{Training Staff and Educators: The Goal is Access}

Post-secondary staff and educators need to have some training on working with disabled students from the perspective of critical social model of disability to actualize the inclusion of mentally disabled students in academic life. Critical social model asks for viewing disability as a social phenomenon beyond the tangible fact 
of physical or mental impairment. The ultimate goal in this model of disability is access through environmental support, inclusion, and consideration. The critical social model of disability we support interrogates separate arrangements for people with disabilities. In higher education setting, it demands an overhaul of institutional policies, infrastructure, and curriculum so that the academy is inclusive of neurodiverse bodies and appreciates their difference-the difference that has the potential of transforming the ableist university. Of course, the purpose of these changes is to produce physical and learning environments in which disability accommodations are unnecessary or needed only infrequently. It also demands that the disabled person's agency always remains intact when they have to avail of accommodations because of the inaccessible and ableist institutional policies and structures. This training is also imperative in the implementation process of accommodations, as teachers must be trained to understand that "Every time I've seen her, she's seemed 'normal'", is not appropriate reasoning for refusing accommodation. Rather, they should be trained to develop course management techniques, curricula and pedagogies that are natively accessible. Here, we would like to specifically address the importance of training educators on the concept of "crip time" from disability culture which takes a less rigid approach to normative time (Gill, 1995). Normative time's understanding is that classes are paced according to the expected amount of time a non-disabled student would be able to complete the coursework. However, this pace does not allow enough time for students with mental disabilities to complete the work should they be experiencing symptoms. By educating faculty about the meaning of "crip time", they may be better able to understand that pacing a class around "ability" is not equitable.

Besides, bipolar disorder may create great conflict in a student's ability to participate in and attend class. Researchers have pointed out that "we tend to view the inability of students to participate in certain aspects of university life...to not be a function of anything inherent to those individuals, but rather the way the university is set up" (Stout \& Schwartz, 2014). Critical social model of disability also situates the educational barrier in the institutional policies and structures, not the student's body. By training educators in bipolar disorder and its symptoms, professors will better understand how this mental disability conflicts with common requirements of participation and attendance in any course. For instance, interacting with one's peers is an important part to expanding knowledge and learning content. However, a student with a bipolar disorder may not learn from the requirement to speak up during class discussions because of the heightened fear of judgement and backlash. A variety of unrelated responses or feelings may prevent them from speaking up at all. If they do speak up, they may be unable to retain any content from the discussion due to anxiety over the judgment of their peers and instructor. Ultimately, professors must know that the belief that the traditional attendance and participation are essential to the learning process is framed from an ableist perspective and alternate pedagogical methods exist to learn and to evaluate student learning. For example, class participation does not always have to happen orally; it can also happen through short, written comments from students on index cards which could then be circulated among small groups by the instructor for carrying on class-wide discussion.

\subsection{Supported Education}

Supported education is a "psychiatric rehabilitation intervention that provides assistance, preparation, and support to persons with mental illness in enrolling in and completing postsecondary educational programs" (Collins \& Mowbray, 2005). Supported education can help mentally disabled students who are unable to attend or participate stay caught up in class, understand and complete material, and stay healthy while attending college. Supported education may also help faculty in interacting with and assisting students with mental disabilities to better understand which accommodations a student may need and why. Research and Innovation Center for Rehabilitation at the Hanze University of Applied Sciences in the Netherlands has published a supported education toolkit for helping academic units to start such programs (Hofstra \& Korevaar, 2016).

\subsection{Funding Student-Driven Self-Support Projects}

Academic accommodations for students with disabilities have been often described as costly and requiring fundamental changes in curriculum and pedagogy. While we urge for these fundamental changes-and they are not as costly when instituted into the university policies than implemented as retrofits-, we also note that colleges also don't pay attention to student support systems which require little investment in new infrastructure or resources. Even the neoliberal universities of these times can easily afford to allot funds for constructing support for low-cost student communities. For example, so few colleges offer encouragement or support to disabled students for organizing their own online campus networks using listservs or other social media where current and prospective students would have safe spaces to exchange personal notes about their classroom experiences, ask questions on academic and social matters, and voice concerns about the campus life. By supporting and maintaining such virtual groups, colleges can not only let students with disabilities form self-supporting communities but also indirectly provide support to at risk students; thus, raising the critically low retention rates for disabled students in higher education.

We also advocate for special programs to mentor students with bipolar and other psychiatric diagnosis by experienced faculty with and without disabilities on the line of other diversity mentoring programs to break the 
circle of isolation, serve as a liaison between students and various services when an intervention is essential, offer emotional and social support at a personal level, and closely track their academic progress-related needs. As the mentoring literature reports again and again, students with diverse characteristics and critical needs can flourish in supportive mentoring relationships (Hastings, Griesen, Hoover, Creswell, \& Dlugosh, 2015). Similarly, we also need faculty coaches with the knowledge of disability studies, event planning experience, and fundraising skills who could train students with mental disabilities to organize small, regional conferences which could function as venues for mingling with students from other colleges. Such conferences can provide opportunities for students to emerge from their disability closets; confront the stigmatizing aspects of their campus life with activism, policy change demands, and communal teach ins about disability hate and bias; form coalitions with other minority groups to strategize disability initiatives; and combine their academic and personal life goals into a purposeful and cohesive whole.

\subsection{Interpersonal Student-Teacher Relationships}

The taboo of interpersonal student-teacher relationships must be challenged as well. College students with disabilities are often experiencing a drastic change in their daily routine when they first move to a university campus. Some students are living without their parents for the first time in their lives, hundreds or thousands of miles away from friends and family that had been their support system before. Interpersonal relationships between students and teachers may prove to be a driving force in encouraging students to seek accommodation when accommodations are necessary. If educators are trained in understanding mental disability and are no longer institutionally steered away from interacting with their students on a personal level, educators can become helpers to students who require accommodations but feel discouraged from disclosing their mental disability for the usual reasons in seeking accommodations. While educators certainly aren't expected to adopt a parental role to their students, students with mental disabilities should be able to express the difficulties and realities of everyday life on campus about their disability to educators. Not only will this allow educators to better understand why a student may need certain accommodations, students are also far more likely to succeed without the invisible barrier between the educator and student.

\subsection{Inclusive Research about Students with Bipolar Disorder}

Finally, we call for more studies about students with bipolar disorder in post-secondary education and we urge disabled students to take a leadership role in undertaking such scholarly projects. We must conduct more research to understand how students with bipolar disorder are functioning in college and what their unmet needs are. Emancipatory and participatory models of research proposed by Disability Studies scholars are specifically suitable for such scholarly and activist undertakings to create a comprehensive picture of life with bipolar disorder in higher education (De Schauwer, Van Hove, Mortier, \& Loots, 2009; O'Day \& Killeen, 2002; Tew, 2006).

Besides the self-support projects discussed above, students and faculty, particularly those with disabilities, must take a lead in organizing small-scale, local and regional disability conferences and symposia on campus to make the university community aware of the mental disability issues, to help the overall student body understand disability rights of their peers, and form a "crip pride" campus community where disabled and nondisabled students could mingle and discuss disability issues.

\section{Conclusion}

These solutions, such as supported education through close mentoring by faculty with background in disability support, availability of small, regional conferences to assist students in coming out of their disability closets, staring social prejudices in the face through student activism to make the age-old stigmas bend down, campuslevel disability education initiatives, and anti-ableist institutional policies, can turn the tide in favor of academic and social inclusivity for students with psychiatric health diagnosis. Our article enforces the relevance of participatory studies of institutional life that record detailed accounts of what students with mental disabilities feel they are missing from their higher education: knowledge of the human body, equitable resources, and an inclusive society. While our recommendations call for a fundamental shift in academic and institutional policies, physical and social structures, curricula and pedagogies, and faculty, staff, and student attitudes, they are essential for the success and well-being of students with mental disabilities, as well as, for transforming our universities into less ableist and more diverse places for learning and teaching.

\section{Acknowledgments}

We thank Devva Kasnitz for advising on the choice of terminology for different mental disabilities. We found her choice of the label "students with mental health diagnoses" particularly helpful. We thank Adam Myer for reading the manuscript and offering usable feedback from the perspective of university disability services and the anonymous reviewers for their helpful comments from a scholarly perspective. Sushil Oswal also wants to thank his sons, Hitender, Lohitvenkatesh and Keshreeyaji Rishabhkumar for their help with the preparation of this manuscript. 


\section{Conflict of Interests}

The authors declare no conflict of interests.

\section{References}

Barton, L. (1998). Developing an emancipatory research agenda: Possibilities and dilemmas. In P. Clough \& L. Barton (Eds.), Articulating with difficulty: Research voices in inclusive education (pp. 29-39). London: Paul Chapman.

Blanco, C., Okuda, M., Wright, C., Hasin, D. S., Grant, B. F., Liu, S. M., \& Olfson, M. (2008). Mental health of college students and their non-college-attending peers: Results from the national epidemiologic study on alcohol and related conditions. Archives of General Psychiatry, 65(12), 1429-1437.

Boys, J. (2014). Doing disability differently: An alternative handbook on architecture, dis/ability and designing for everyday life. New York, NY: Routledge.

Campbell, F. (2009). Contours of ableism: The production of disability and abledness. London: Palgrave Macmillan.

Carel, H. (2012). Phenomenology as a resource for patients. Journal of Medicine and Philosophy: A Forum for Bioethics and Philosophy of Medicine, 37(2), 96-113.

Carel, H. (2017). Even ethics professors fail to return library books. Philosophy, Psychiatry, \& Psychology, 24(3), 211-213.

Chrisman, W. (2011). A reflection on inspiration: A recuperative call for emotion in disability studies. Journal of Literary \& Cultural Disability Studies, 5(2), 173-184.

Clark, M. A. (2006). Adult education and disability studies, an interdisciplinary relationship: Research implications for adult education. Adult Education Quarterly, 56(4), 308-322.

Collins, M. E., \& Mowbray, C. T. (2005). Higher education and psychiatric disabilities: National survey of campus disability services. American Journal of Orthopsychiatry, 75(2), 304-315.

Crow, L. (1996). Including all of our lives: Renewing the social model of disability. In J. Morris (Ed.), Encounters with strangers: Feminism and disability (pp. 206-226). London: Women's Press.

Davidovitch, N., \& Soen, D. (2006). Class attendance and students' evaluation of their college instructors. College Student Journal, 40(3), 691-704.

De Schauwer, E., Van Hove, G., Mortier, K., \& Loots, G. (2009). 'I need help on Mondays, it's not my day. The other days, I'm ok': Perspectives of disabled children on inclusive education. Children \& Society, 23(2), 99-111.

Demery, R., Thirlaway, K., \& Mercer, J. (2012). The experiences of university students with a mood disorder. Disability \& Society, 27(4), 519-533.

Dinishak, J. (2016). The deficit view and its critics. Dis- ability Studies Quarterly, 36(4). http://dx.doi.org/ $10.18061 /$ dsq.v36i4.5236

Donaldson, E. J. (2015). Beyond a beautiful mind: Schizophrenia and bioethics in the classroom. Disability Studies Quarterly, 35(2). http://dx.doi.org/ 10.18061/dsq.v35i2.4635

Eisenberg, D., Downs, M. F., Golberstein, E., \& Zivin, K. (2009). Stigma and help seeking for mental health among college students. Medical Care Research and Review, 66(5), 522-541.

Garland-Thompson, R. (1997). Extraordinary bodies: Figuring physical disability in American culture and literature. New York, NY: Columbia University Press.

Ghai, A. (2003). (Dis)embodied form: Issues of disabled women. New Delhi: Shakti Books.

Gill, C. J. (1995). A psychological view of disability culture. Disability Studies Quarterly, 15(4), 16-19.

Goffman, E. (2009). Stigma: Notes on the management of spoiled identity. New York, NY: Simon \& Schuster. (Original work published 1963)

Grasgreen, A. (2014, April 2). Students with disabilities frustrated with ignorance and lack of services. Inside Higher Education. Retrieved from www.insidehighered.com

Halawah, I. (2006). The impact of student-faculty informal interpersonal relationships on intellectual and personal development. College Student Journal, 40(3), 670-678.

Hansen, N. D., Pepitone-Arreola-Rockwell, F., \& Greene, A. F. (2000). Multicultural competence: Criteria and case examples. Professional Psychology: Research and Practice, 31(6), 652-660.

Harsh, M. (1993). Women who are visually impaired or blind as psychotherapy clients: A personal and professional perspective. Women and Therapy, 74(3/4), 55-64.

Hastings, L. J., Griesen, J. V., Hoover, R. E., Creswell, J. W., \& Dlugosh, L. L. (2015). Generativity in college students: Comparing and explaining the impact of mentoring. Journal of College Student Development, 56(7), 651-669.

Hofstra, J., \& Korevaar, L. (2016). Supported education toolkit. Groningen: Research and Innovation Center for Rehabilitation.

Hornstein, G. (2017, March 26). Why I dread the accommodations talk. The Chronicle of Higher Education. Retrieved from www.chronicle.com

Jones, N., \& Brown, R. (2012). The absence of psychiatric $C / S / X$ perspectives in academic discourse: Consequences and implications. Disability Studies Quarterly, 33(1). http://dx.doi.org/10.18061/ dsq.v33i1.3433

Kerschbaum, S. L., Garland-Thomson, R., Oswal, S. K., Vidali, A., Ghiaciuc, S., Price, M., . . Samuels, E. (2013). Faculty members, accommodation, and access in higher education. Profession. Retrieved from profession.mla.hcommons.org/2013/12/09/faculty -members-accommodation-and-access-in-higher- 
education

Kimball, E. W., Wells, R. S., Ostiguy, B. J., Manly, C. A., \& Lauterbach, A. A. (2016). Students with disabilities in higher education: A review of the literature and an agenda for future research. In M. Paulsen (Ed.), Higher education: Handbook of theory and research (pp. 91-156). Dordrecht: Springer.

Kiuhara, S. A., \& Huefner, D. S. (2008). Students with psychiatric disabilities in higher education settings: The Americans with Disabilities Act and beyond. Journal of Disability Policy Studies, 19(2), 103-113.

Morris, J. (1991). Pride against prejudice: A personal politics of disability. London: Women's Press.

Mullins, L., \& Preyde, M. (2013). The lived experience of students with an invisible disability at a Canadian university. Disability \& Society, 28(2), 147-160.

National Center for Education Statistics. (2016). Fast facts: Students with disabilities (NCES Report 2016014). Washington, DC: US Department of Education.

National Institute of Mental Health. (2006). Mental disorders in America (NIH Publication no 06-4584). Bethesda, MD: National Institute of Mental Health.

Nicolas, M. (2017). Ma(r)king a difference: Challenging ableist assumptions in writing program policies. WPA: Writing Program Administration-Journal of the Council of Writing Program Administrators, 40(3), 10-22.

Nitzburg, G. C., Russo, M., Cuesta-Diaz, A., Ospina, L., Shanahan, M., Perez-Rodriguez, M., . . . Burdick, K. E. (2016). Coping strategies and real-world functioning in bipolar disorder. Journal of Affective Disorders, 198, 185-188.

O'Day, B., \& Killeen, M. (2002). Research on the lives of persons with disabilities: The emerging importance of qualitative research methodologies. Journal of Disability Policy Studies, 13(1), 9-15.

Olkin, R. (1999). What psychotherapists should know about disability. New York, NY: Guilford Press.

Oswal, S. K. (2013). Ableism. Kairos: A Journal of Rhetoric, Technology, and Pedagogy, 18(1). Retrieved from kairos.technorhetoric.net/18.1/coverweb/yergeauet-al/pages/ableism/index.html

Oswal, S. K. (2017). Disabling policies and exclusionary infrastructures: A critique of the AAUP report. In D. Bolt \& C. Penketh (Eds.), Disability, avoidance and the academy (pp. 33-44). London: Routledge.

Oswal, S. K. (2018). Can workplaces, classrooms, and pedagogies be disabling? Business and Professional Communication Quarterly, 81(1), 3-19.

Price, M. (2011). Mad at school: Rhetorics of mental disability and academic life. Ann Arbor, MI: University of Michigan Press.

Price, M., Salzer, M. S., O’Shea, A., \& Kerschbaum, S. L. (2017). Disclosure of mental disability by college and university faculty: The negotiation of accommodations, supports, and barriers. Disability Studies Quarterly, 37(2). http://dx.doi.org/10.18061/dsq. v37i2.5487

Priestley, M. (1995). Commonality and difference in the movement: An "association of blind Asians" in Leeds. Disability \& Society, 10, 157-170.

Pryal, K. R. G. (2010). The genre of the mood memoir and the ethos of psychiatric disability. Rhetoric Society Quarterly, 40(5), 479-501.

Roets, G., Kristiansen, K., Van Hove, G., \& Vanderplasschen, W. (2007). Living through exposure to toxic psychiatric orthodoxies: Exploring narratives of people with 'mental health problems' who are looking for employment on the open labour market. Disability \& Society, 22(3), 267-281.

Runswick-Cole, K., \& Goodley, D. (2013). Resilience: A disability studies and community psychology approach. Social and Personality Psychology Compass, 7(2), 67-78.

Shakespeare, T., \& Watson, N. (2001). The social model of disability: An outdated ideology? In S. N. Barnartt \& B. M. Altman (Eds.), Exploring theories and expanding methodologies: Where we are and where we need to go (pp. 9-28). Bingley: Emerald Group.

Sharpe, M. N., Bruininks, B. D., Blacklock, B. A., Benson, B., \& Johnson, D. M. (2004). The emergence of psychiatric disabilities in postsecondary education. Examining Current Challenges in Secondary Education and Transition, 5(1), 1-6.

Silvers, A. (1994). 'Defective' agents: Equality, difference and the tyranny of the normal. Journal of Social Philosophy, 25(S1), 154-175.

Stout, A., \& Schwartz, A. (2014). It'll grow organically and naturally: The reciprocal relationship between student groups and disability studies on college campuses. Disability Studies Quarterly, 34(2). http://dx.doi.org/10.18061/dsq.v34i2.4253

Tew, J. (2006). Understanding power and powerlessness: Towards a framework for emancipatory practice in social work. Journal of social work, 6(1), 33-51.

Thomas, C. (1999). Female forms. Experiencing and understanding disability. Buckingham: Open University Press.

Trivedi, P., \& Wykes, T. (2002). From passive subjects to equal partners: User involvement in research. A review. British Journal of Psychiatry, 181, 468-472.

Union of the Physically Impaired Against Segregation. (1976). Fundamental principles of disability. London: Union of the Physically Impaired Against Segregation.

Venville, A., Street, A., \& Fossey, E. (2014). Student perspectives on disclosure of mental illness in postcompulsory education: Displacing doxa. Disability \& Society, 29(5), 792-806.

Wilson, K., Getzel, E., \& Brown, T. (2000). Enhancing the post-secondary campus climate for students with disabilities. Journal of Vocational Rehabilitation, 14(1), 37-50.

World Health Organization. (1992). The ICD-10 classification of mental and behavioural disorders: Clinical descriptions and diagnostic guidelines (Vol. 1). Geneva: World Health Organization. 


\section{About the Authors}

Allison K. Kruse is a graduate of the University of Washington's Technical Communication program in the School of Interdisciplinary Arts and Sciences which excels in accessible design, human-computer interaction design, and user experience (UX). Her interests include human-centered design, disability studies, and technical communication. Besides her scholarship in the area of disability studies and accessible design, Allison has also conducted field research in prototype design and usability testing at the University of Washington. She is presently looking for opportunities in the areas of content development and writing, technical communication, publishing and editing, and related research.

Sushil K. Oswal (Dr.) is an Associate Professor of $\mathrm{HCl}$ and Accessible Design in the School of Interdisciplinary Arts and Sciences and an affiliate faculty in Disability Studies at the University of Washington. His PhD research focused on the application of environmental science and environmental technologies in the research for innovative cosmetics formulations and corporate policy in a Japanese multinational corporation. His current interdisciplinary and international research deals with information and communication technology development's (ICTD) role in human health development projects, as well as, the impact of ICTD projects sponsored by the governments, international monetary institutions, and nongovernmental organizations of the global north on the rural women with disabilities in the global south. He is also working on a longitudinal study of interaction design of self-service digital kiosks in aviation and banking. His recent interdisciplinary accessible design and disability studies work is available at journals.sagepub.com/toc/bcqe/81/1 